\title{
Central Retinal Vein Occlusion
}

National Cancer Institute

\section{Source}

National Cancer Institute. Central Retinal Vein Occlusion. NCI Thesaurus. Code C118859.

Blockage of the central retinal vein. 